\title{
From the Holocene to the Anthropocene: Climate of the last 1,000 Years
}

\section{Jed Kaplan}

Institute of Plant Sciences, University of Bern, Bern, Switzerland; jed.kaplan@ips.unibe.ch

The 4th International NCCR Climate Summer School was held from 28 August to 2 September in picturesque Grindelwald, Switzerland. The Summer School attracted a record number of applicants and was attended by 72 participants from 14 countries across four continents.

Twelve keynote speakers-leaders in the fields of climate analysis, reconstruction, and attribution-highlighted research on climate change and variability over the past millennium. Thematic poster sessions gave the participants ample opportunity to discuss their own research projects with peers and experienced researchers. Four elective workshops gave participants hands-on experience of both the strengths and pitfalls of paleoclimate reconstruction using modelling, and terrestrial, lacustrine and historical proxy records. A resounding message of this year's Summer School was that the current climate is outside the realm of natural variability as observed over the past 1,000 years and definitely perturbed by human activities.

The Summer School took place just one week after the massive summer floods that ravaged the Central and Eastern Alps. On the bus ride to Grindelwald, participants witnessed firsthand the destructive power of the climate system. During the week, the development of hurricane Katrina lent an additional sense of urgency to the proceedings. Heinz Wanner, NCCR Climate Director, commented that discussions on climate change had been much more intense than in previous years. The Summer School itself was blessed with excellent late-summer mountain weather and participants took advantage of excursions to the ridge tops, forests and glacial canyons surrounding Grindelwald.

NCCR Climate strongly promotes the education of young researchers. Created to encourage exchanges between $\mathrm{PhD}$ students, post-docs and leading climate researchers, the International NCCR Climate Summer School has become a highly appreciated opportunity to share scientific ideas and create cross-disciplinary links. Each Summer School consists of keynote lectures, workshops, poster sessions and excursions to research sites, and is open to young researchers worldwide. A small number of grants are available for students from developing countries.

For details on the 2006 Summer School please see: www.nccr-climate.unibe.ch/events_summerschool06

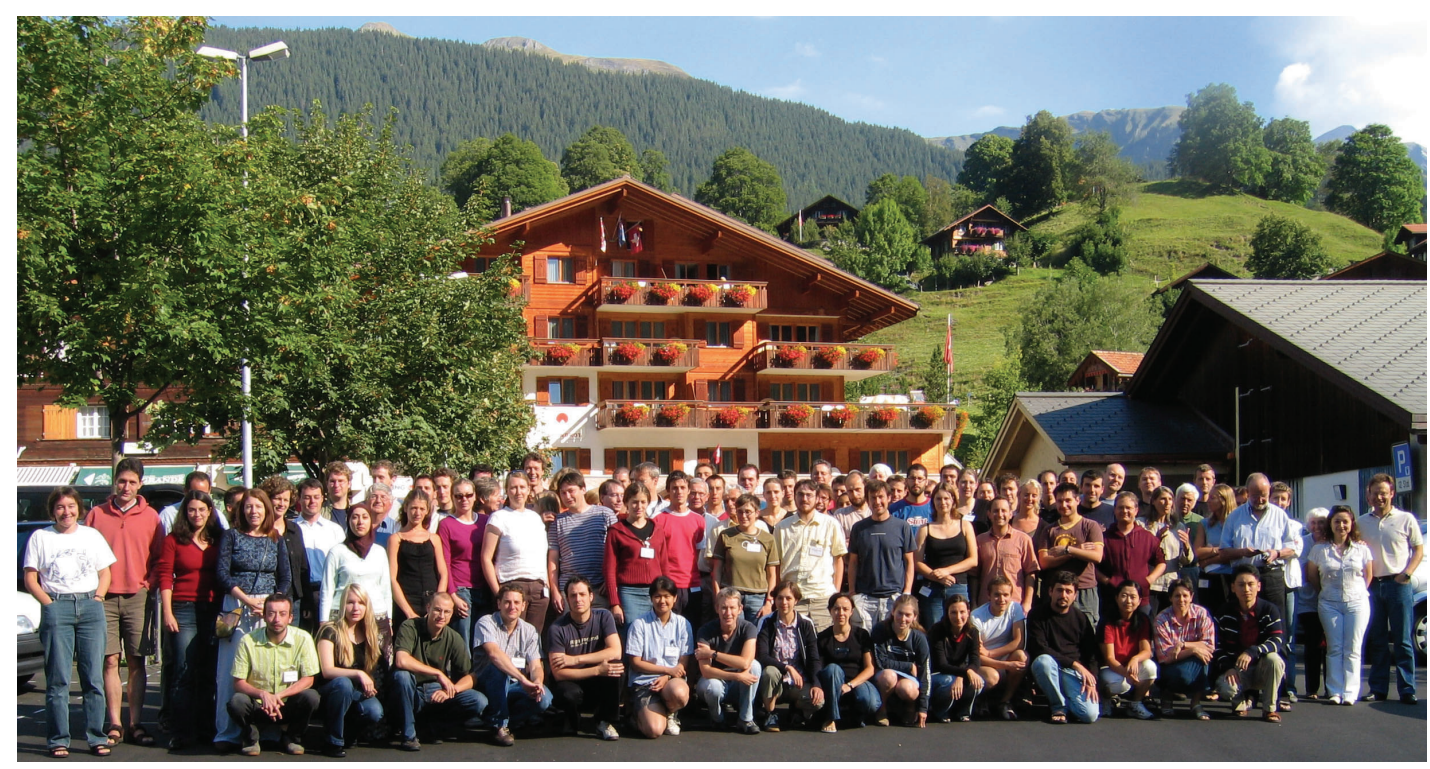

The participants group of the 4th International NCCR Climate summer school in Grindelwald - Switzerland 